\title{
Introduction to Pragmatism and Psychologism
}

\section{Rosa M. Calcaterra and Roberta Dreon}

\section{(2) OpenEdition}

\section{Journals}

Electronic version

URL: http://journals.openedition.org/ejpap/997

DOI: 10.4000/ejpap.997

ISSN: 2036-4091

\section{Publisher}

Associazione Pragma

\section{Electronic reference}

Rosa M. Calcaterra and Roberta Dreon, «Introduction to Pragmatism and Psychologism », European Journal of Pragmatism and American Philosophy [Online], IX-1 | 2017, Online since 22 July 2017, connection on 23 September 2020. URL : http://journals.openedition.org/ejpap/997 ; DOI : https:// doi.org/10.4000/ejpap.997

This text was automatically generated on 23 September 2020 .

\section{c)}

Author retains copyright and grants the European Journal of Pragmatism and American Philosophy right of first publication with the work simultaneously licensed under a Creative Commons AttributionNonCommercial-NoDerivatives 4.0 International License. 


\title{
Introduction to Pragmatism and Psychologism
}

\author{
Rosa M. Calcaterra and Roberta Dreon
}

\section{AUTHOR'S NOTE}

Although this introduction has been a joint effort, Rosa Calcaterra wrote $\$ 1$ while Roberta Dreon wrote $\$ 2$.

\section{$\S 1$}

1 According to the paradigmatic formula offered by Kant, ${ }^{1}$ the philosopher's task consists of demonstrating "how we ought to think" as opposed to "how we do think" - that is, logical rules or norms must be separated from the functioning principles of the human mind or from psychological laws. As it is well-known, in the "Preface" to the second edition of the Critique of Pure Reason, the German philosopher stands against "some moderns" who "have thought to enlarge" logic "interpolating psychological chapters about our different cognitive powers (about imagination, wit) or metaphysical chapters about the origins of cognition or the different kinds of certainty in accordance with the diversity of objects (about idealism, skepticism, etc), or anthropological chapters about our prejudice (about their causes or remedies)." In his view, this does not involve an "improvement" but a "deformation" of logic, so such observations must be set aside when one seeks to deal with the principles of the correct or rational way of thinking, knowing and acting. Kant explains that psychological, metaphysical, anthropological clarifications go beyond the boundaries of logic, which are "determined quite precisely by the fact that logic is the science that exhaustively presents and strictly proves nothing but the formal rules of all thinking (whether this thinking be empirical or a priori, whatever origin or object it may have, and whatever contingent or natural obstacles it may meet with in our minds)." ${ }^{2}$ Thus, for Kant as well as for all those who have accepted his 'normative' approach to logic, the "how we do 
think" falls out the realm of logic as pivotal subject of philosophy, whose task is indeed to grasp and define the very features and conditions of human thought. Authors such as Frege and Husserl apparently adopted such a stance that they contrasted to the socalled "psychologist" account of knowing and thinking processes.

However, there is great difficulty in establishing clearly what the term "psychologism" means and the authors who are usually listed under this label or are placed in the ranks of anti-psychologists often present aspects that are contrary to the ordinary classifications and even clash with their own statements of intellectual heredity. Indeed, what is called into play is the primary task that the prevailing Western philosophical tradition has assigned itself since its origins, namely the prerogative of winning access to universal knowledge and values, in turn conceived as the very apotheosis of rationality in abstraction from the affective-sensorial sphere of the human being. In addition, classifications largely depend on the interpretations of the philosophical texts that are taken into account, that is, on the reading and understanding of their most salient aspects, as well as on the theoretical perspectives that each interpretation inevitably brings with itself. In this light one can, for instance, read a paradigmatic case of the intricate debate on psychology: Hegel's criticism of Kant, the philosopher who provided the classic formulation of the difference between psychologists and normativists but whom Hegel without hesitation branded a psychologist.

3 Venturing a very condensed summary, let us remember that Hegel's controversial argument concerns the Kantian deduction of the categories and its major aspects, that is, the distinction between intuition and concept, or between the empirical multiplicity and the synthetic unity of the transcendental apperception, as well as the role of imagination in the formulation of judgments. Above all, Hegel reproaches Kant for concentrating on the analysis of the cognitive faculties without being able to overcome subjectivism, that is to say without being able to account for the subject and object "zweyseitige" - the identity in the difference - which originally links the intellect and the world of the phenomena of nature. ${ }^{3}$ In short, the accusation of psychologism is identified with the accusation of subjectivism that Hegel addresses to Kant, stigmatizing in particular the causal relationship that the latter would establish between intellect and imagination, so that the unity of the Kantian ego would be inevitably compromised by the importance attributed to the realm of subjectivity. Alternatively, Hegel's intent is to prove the original unity of subjectivity and objectivity, activity and passivity, which, in his opinion, appears in consciousness; therefore he commits himself to offering an account of the categorical apparatus capable of capturing its common belonging to thought and being.

This is not the place to discuss the correctness of the arguments used by Hegel to recommend the overcoming of the "psychologism" that he attributes to Kantian logic. The fact remains that this polemical stance extends throughout the entire spectrum of Hegel's speculation; in fact he defines Kantian transcendentalism as "psychological idealism" also in Wissenshaft der Logik. ${ }^{4}$ In any event, the identification of psychology and subjectivism on which the Hegelian criticism of Kant revolves is still one of the leitmotifs of the debate on the topic of the present Symposium.

5 We must also remember that the term "subjectivism" has different philosophical meanings - the Humean, the Cartesian-Kantian, the Husserlian, or the Fregean - each of which inevitably bears on the understanding of psychologism and its normative 
counterpoint. Indeed, the word 'subjectivism' may hold a logical-semantic value which is close to all that can be attributed to the realm of the particular and the contingent, of the merely individual or even idiosyncratic; or rather a value that implies the recognition of a universal sharing of certain aspects of the human mind. Notwithstanding the inexhaustible commitment of both philosophy and psychology to defining these universal traits, the question of psychologism is often compromised by a confusion between the idea that there are 'mental states' and the idea that there is or should be a "study of mental states." From this point of view, one can argue, for example, for the interpretation of Frege as paradigmatic with regard to the proximity of anti-psychologism with so-called logical platonism, a closness which is indeed questionable.

6 The close kinship between logical-semantic Platonism and a logical theory of an antipsychological moldis signaled by several interpreters of Fregean viewpoint; for example, Susan Haack identifies this mold is conjunction as the source of Frege's antipsychologism, insisting on his affirmation that logic has nothing to do with mental processes. Above all, she rejects the Fregean position, arguing that the Platonic structure of anti-psychologism implies a lack of recognition of the 'public' nature of logical rules; she favors a "moderate psychologism" that attributes to logic a prescriptive function for mental processes especially insofar as they are linguistic processes - that is, that asserts that logical laws establish relationships between propositions or sentences. Within this last definition, Haack includes Pierce and James, although differently, and it is interesting to note that she formulates in their wake a logical-epistemological theory which aims to safeguard both the causal role of sensory experience and the evaluation component of mental processes. ${ }^{5}$

7 There could be many other examples of the variety of ways of codifying psychology and its allies as well as its opponents. As a matter of fact, the philosophy of the past century contains a dramatic oscillation between a strong condemnation of psychologism across-the-board - targeting phenomenology as well as certain important areas within analytic philosophy - and a more recent trend in the philosophy of mind and in the cognitive sciences to naturalize philosophical inquiries in a way that welcomes the translations of existing philosophical vocabularies into psychological ones. Additionally, for several decades there has been a widespread effort to re-elaborate a particularly dense and intricate group of theoretical-methodological conceptual pairs that nourish the oppositional mentality framing the traditional distinction between philosophy and psychology and, subsequently, the same opposition of Psychologism and anti-psychology or normativism. I refer mainly to concepts such as "physical" and "psychic," "subjective" and "objective," "external" and "internal," "relational" and "absolute," "dynamic" and "structural," "individual" and "social," "universal" and "historical-cultural," and ultimately "descriptive" and "normative."

8 As a first approximation, it can be said that attention to the dimension of language and at the same time the enhancement of the category of sociality have formed the cornerstones of a broad revision of these key notions of the Western philosophical vocabulary, a revision that in essence has promoted the treatment of these conceptual pairs in a functional rather than dichotomous sense. In a nutshell, what has come to be questioned is the traditional foundationalist stance that underlies the oppositional mentality, that is, the search for an ab-solutum primum, whether logical or ontological, on which to support the validity of our epistemology and values. In this regard, very 
important contributions from the Wittgensteinian perspective have been offered, especially where the Austrian philosopher shows the extreme difficulty of drawing sharp boundaries between one concept and another, but also from emblematic areas of post-neopositivist analytical philosophy - from Willard Quine to Wilfrid Sellars and Donald Davidson - as well as from prominent representatives of post Husserlian phenomenology - such as Adolf Reinach, Alfred Schütz and Maurice Merleau-Ponty. But no less interesting is the contribution offered by the Pragmatist elaborations of the concept of experience, through which the dichotomous mentality that governs Western philosophical tradition and, specifically, its typical fundamentalist stance, are variously challenged.

9 From an overall point of view, it can be said that, differently from the modern empiricism of Locke and Hume, the Pragmatist notion of experience consists of the elaboration of a form of epistemological holism that excludes the absolute priority of sensory data over concepts or their fundamental role in the formation of beliefs and, therefore, also any ultimate or self-sufficient criterion defining their own validity. In other words, according to classical Pragmatists, an inter-relational and dynamic view of the cognitive processes must be adopted, for which the isolationist theory of sensations deriving from Hume, on which the foundationalist ambition of tradition empiricist revolves, is regarded as untenable. Pragmatists seek instead to highlight the irreducible intersection of the sensory/affective field with the intellectual; more precisely, they suggest the virtuous circularity between the concrete field of action, the logical-semantic sphere, and the cognitive sphere. From this follows a Pragmatic understanding of the notion of "foundation," which tends to combine the epistemic and ethical criteria of truth and objectivity with the domain of action, as a socially tangible demonstration of the functional polyvalence of the concept of experience - its functioning as instrument for the formation of beliefs, as well as its work as a concrete source of their correction or denial.

It should be emphasized that the pragmatic notion of "foundation" does not correspond to a pure and simple reversal of the terms of the rationalist/idealistic relationship between the conceptual domain and the empirical domain or, more generally, between theory and practice. Rather, it is employed to give a more meaningful sense to the usual statement that ideas or theories have impact on practice, acknowledging the latter as a basic component not only of knowledge building but also of the awareness of their fallibility in principle. This is a typical attitude of both classic and contemporary pragmatist thinking, but it remains the fact that according to the enemies of psychologism, James, Dewey, and Mead - though not Peirce - where responsible for a "psychologist fallacy" consisting in conflating objective causes or necessary rules of logical processes with subjective reasons; as a consequence, pragmatist conceptions sharing Dewey's understanding of logic as the natural history of thought have been criticized for missing the very point of logic altogether. Yet for the pragmatists the very dualism of logic and psychology was a problematic theoretical constructions that needed to be submitted to critical inquiry. Indeed, the very gist of pragmatist arguments such as the reject of the fact/value dichotomy in the name of the intertwinement of logic with the affective, biological and cultural sphere could be read as attempt at rethinking the relationships between logic and psychology. And pragmatist "cultural naturalism" can be seen as similarly attempting to overcome the psychologism/anti-psychologism divide. 


\section{$\S 2$} the ways in which the founders of Pragmatism, Peirce and James, can be situated in the Psychologism/anti-Psychologism debate. The many forms of anti-Psychologism are placed under investigation by the authors of this volume, definitively suggesting a multifaceted picture of Psychologism. If the whole issue could be simplified in the question whether or not the Pragmatists were Psychologist or anti-Psychologist, the general result of the current inquiry is that the problem cannot be solved by means of a mere ascription or non-attribution of these labels to them. Although reasonable arguments can be found for sustaining the thesis that both Peirce and James were antiPsychologist - in very different ways and with very different styles - the crucial point emerges that they shared a general critical stance towards formulating the question in terms of facile dichotomies.

12 A series of papers - Tiercelin's, Sanfelix's and Lanfredini's - help us examine this complex variety of implications. Claudine Tiercelin explicitly faces both the main charges basically characterizing a standard critical stance towards a Psychologist attitude in logic: that on the one hand, Psychologism in logic would involve a general collapsing of the normative domain of logical rules into the empirical ways we de facto think and reason; and that on the other hand, a psychological reading of logic would imply its reduction to mere subjective conditions of thought. The second feature is clearly shared by Peirce's strong criticism of introspection considered as a kind of immediate approach to certain knowledge, namely as a privileged grasp that avoids the allegedly ubiquitous doubt concerning our experience of the external world according to a Cartesian stance. Tiercelin's paper stresses Peirce's clear preference for an externalist treatment of typically psychological features such as sensations, emotions and beliefs - a point that will be further developed in positive and promising ways by Giovanni Maddalena's essay and by Matteo Santarelli's article.

Dealing with the normative-empirical divide is a more complex issue in Peirce's theory of the sign and Tiercelin tackles the problem in its complexity. First of all she points out the general Pragmatist dislike of the standard dualism between "how we would think" according to logical rules and "how we actually think" in actual conditions of human life. Secondly she stresses that the role of logic in semiotics cannot be reduced to formal logic and to mathematical calculus, because logic has not simply to apply rules of reasoning; logic must also consider what reasoning is, its different forms and how it should be developed. Thirdly Tiercelin sustains the thesis that Peirce elaborated an original conception of normativity and of the relation between norms and nature, allowing him to consider logical laws as emerging from nature: her central argument is that, although radical indeterminacy is the dominant character of evolution, the growth of concrete reasonableness produces a logical field where we have to understand truth as a normative property. As she writes: "[l] ogical norms are inferential norms, governing what we can expect an agent to believe, if he has certain beliefs." In this interpretation Peirce seems to occupy a third, intermediate position between the standard logical anti-Psychologism à la Frege and Psychologism as reductive naturalism. 

James: can James' position on epistemology be characterized as involving a form of reductive naturalization à la Quine? His paper provides an answer by means of an innovative confrontation between James' conception of psychology as a science, his theory of knowledge, and Wittgenstein's Tractatus Logico-Philosophicus. His basic assumption is that Wittgenstein cannot be confined as a merely critical reader of James and that it can be philosophically fruitful identifying some aspects of both James' Variety and Principles which were or could be shared by Wittgenstein himself. Sanfelix claims that James was not simply reducing epistemology to psychology, because he was strongly conscious of the controversial status of many psychological concepts as well as of the inability of psychology to pose the question about the possibility of knowledge in general. Nevertheless, in Sanfelix's interpretation, James' approach to epistemology could also teach something to the early Wittgenstein: theory of knowledge cannot be simply and completely translated into a logic disentangling psychological propositions, because such a move leaves some crucial metaphysical issues outside the door. This is why James was brave enough to try finding a substantive answer, represented by his genetic naturalism. Logical apriori structures have to be explained as the result of natural selection: although being the ultimate outcome of a merely contingent development, they were transmitted and became part of the innate endowment of the human mind, surprisingly opening the door for a normative space born out of chance. Even Sanfelix' interpretation of James' position - although with a different style - tends to strengthen the idea of the Pragmatists as suggesting a third way between Psychologism and anti-Psychologism; here logic and epistemology seem to be anchored in human developmental anthropology, although they represent the emergence of a new field of normative relationships that cannot be reduced to previous forms of living interactions with the environment. Roberta Lanfredini understands James' anti-Psychologism as a form of neutralization. In her reading of James, neutralizing a psychologistic approach to experience means basically denying any form of privilege to consciousness as well as any priority to a cognitive position on experience. Therefore the net outcome of James' Essays on Radical Empiricism is a conception of pure experience as impersonal and equidistant from both objectivity and subjectivity. Experiential features can be distinguished on a functional level but are not to be assumed as ontologically different: different kinds of order are legitimate and both Husserl's basic asymmetry in favour of the noetic pole and his eminently cognitive conception of experience have to be rejected in pursuing a radical thought about experience. Nonetheless Lanfredini argues that both Husserl's and James' neutralization are not radical enough because they would share a preeminence of the present in reference to the other temporal dimensions as well as an idea of experience as made of discrete parts that should be overcome.

Claudia Cristalli's and Alexander Feodorov's papers shed some light on two particular aspects of Peirce's philosophy, playing an important role in configuring his peculiar position in the Psychologism - anti-Psychologism debate. Cristalli basically endorses an interpretation of Peirce as a clear-cut anti-Psychologist in logic from his very beginnings, and so has to tackle the problem of Peirce's strong interest in doubt and belief in the period between 1868 and 1885 - namely with widely psychological concepts troubling his whole philosophical oeuvre. In order to understand better those 
years, Cristalli inquiries into Peirce's strong interest in experimental psychology and its role in his philosophy. She strongly stresses the experimental-psychological preference for a quantitative and inferential approach to psychic phenomena as a key element in overcoming the standard introspective and qualitative oriented approach to psychology. This conversion of psychology into a properly scientific discipline should have represented for Peirce the chance to consider also the practical dimension of logic, which would consist in testing scientific inferences by considering their material consequences.

17 Feodorov pays special attention to the concept of habit in Peirce's thought as an important element in understanding his non-Psychologistic stance. Feodorov reconstructs the origin of the Pragmatists' strong interest in habit in Alexander Bain's theory of belief, which was very influential on the first Pragmatists. Bain shifted the concept of belief out of an eminently cognitive interpretation - according to which a belief should basically be a meaning deposited in the mind or a mental state - into a practical frame: a belief is primarily a disposition to act. Peirce's emphasis on beliefs as habits of action clearly developed Bain's idea, although he criticised the psychological interpretation of the concept, according to Feodorov. In his reading of Peirce, the Pragmatist's idea of habit was preserved from becoming a merely psychological concept because Peirce extended it out of the human environment into the physical world, by adopting a conception of habit concerning the evolution of the whole universe. In this perspective cosmology appears to be a true antidote to Psychologism.

To conclude this synthetic survey, both Maddalena's and Santarelli's papers seem to go beyond a defense of the Pragmatists' position with regard to the whole issue we are discussing. On the contrary, they venture into a more open exchange between philosophy and psychology, inspired by Peirce's semiotic philosophy. Maddalena tends to scale down the early Peirce's anti-psychologist attitude in logic by characterizing it as a general criticism to an inappropriate mixture of disciplines inquiring into the process of reason. This concern did not prevent Peirce from denying the importance of widely psychological features in human reasoning, such as feelings, sensations, beliefs, habits and doubts that could be reinterpreted in externalist terms. Moreover Maddalena argues that during the years when Peirce developed a synthetic approach by means of the so-called existential graphs, he was more open to including psychological elements in his philosophical approach in order to avoid the problematic distinction between the phenomenological level of analysis and the psychological, adopted in the previous period.

This is the premise for a challenging comparison between Peirce and Jung on their respective conceptions of the conscious self as emerging out of a collective unconscious. In Peirce's case the ego loses its allegedly omnipotent power as the subject of meaning; on the contrary, it seems to grow out of the collective semiotic processes, which largely precede the intervention of individual egos. In turn, individual egos appear as the sources of transformation of larger collective symbolic processes, rather than as the very points of departure of knowledge. In both authors Maddalena sees "selfhood as a result to be attained within a broader flux of experience," whose symbolic, although impersonal, characterization appears crucial in the synthetic processes giving rise to individualized selves.

Matteo Santarelli sustains the thesis that Peirce's externalist re-interpretation of many crucial psychological concepts could leave more room for developing a psychology of 
inner states focused on the communicative and semiotic processes in which they emerge and are configured. In other terms, Peirce's criticism of introspection as an allegedly immediate grasp of psychological phenomena could represent a chance for a different approach to them - a kind of third, non-dualistic approach avoiding both internalism and behavioristic eliminativism, focusing on the collective semiotic processes in which psychological phenomena would be shaped.

Rethinking Peirce's philosophy is considered as an opportunity for re-stablishing psychological categories on a non-Psychologist ground - namely a ground which is not the idea of introspection as an immediate grasp of intra-psychic phenomena. A first attempt in developing this ambitious project is represented by Santarelli's inquiry into the psychology of attachment, where both social relations and their significance clearly appear as the ground out of which individual feelings, beliefs and dispositions to act emerge and are configured.

Once more this topic is a case where classical Pragmatism reveals a complexity of approach frustrating the desire for clear-cut simple and binary solutions; dualistic stances show their inappropriateness, and alternative, not already guaranteed ways of investigation have to be attempted.

\section{BIBLIOGRAPHY}

FERRARIN A., (2016), Il pensare e l'io. Hegel e la critica di Kant, Roma, Carocci.

HAACK S., (1978), Philosophy of Logics, Cambridge, Cambridge University Press.

HAACK S., (1993/2009), Evidence and Inquiry: Towards Reconstructions in Epistemology, Oxford, Blackwell, expanded ed. Evidence and Inquiry: A Pragmatist Reconstruction of Epistemology, Amherst (Ma), Prometheus Books,.

HEGEL W.F., (1832), Wissenshaft der Logik I/II.

HEGEL W.F., (1969-71), Werke in zwanzig Bänden, Suhrkamp.

KANT I., (1998), Critique of Pure Reason, transl. by P. Guyer \& A. Wood, Cambridge, Cambridge University Press.

PORTAS G., (2015), “La errónea comprensión del problema del psicologismo en Susan Haack,” Cognitio, 12 (1).

\section{NOTES}

1. See I. Kant, Logik, Hrsg. Von G. B. Jäsche, Konisberg, F. Nicolovius, 8.

2. Kant (1998: 106-7).

3. Cfr. Particularly Hegel (1969-71: 300-30).

4. Cfr. Hegel (1832: Vol. II, 261). Among the most recent critical discussion of the subject, see Ferrarin 2016. 
5. Cfr. Haack 1978, and 1993/2009. Haacks' interpretation of Frege as a "Platonist antipsychologist" as well as her own alternative logic proposal is firmly criticized, for instance, in Portas 2015.

\section{AUTHORS}

\section{ROSA M. CALCATERRA}

Università degli Studi Roma Tre

rosamaria.calcaterra[at]uniroma3.it

\section{ROBERTA DREON}

Università Ca' Foscari di Venezia

robdre[at]unive.it 